\title{
CORRECTION
}

\section{Correction to: Production of referring expressions in Arabic}

\author{
Imtiaz Hussain Khan ${ }^{1}[$
}

Published online: 13 November 2019

(c) Springer Science+Business Media, LLC, part of Springer Nature 2019

\section{Correction to: \\ International Journal of Speech Technology (2016) 19:385-392 \\ https://doi.org/10.1007/s10772-015-9282-8}

This work was supported by a King Abdulaziz University (KAU) funding (Grant no. 611-009-D1433). The author thanks KAU for their financial support.

Publisher's Note Springer Nature remains neutral with regard to jurisdictional claims in published maps and institutional affiliations.

The original article can be found online at https://doi.org/10.1007/ s10772-015-9282-8.

Imtiaz Hussain Khan

ihkhan@kau.edu.sa

1 Department of Computer Science, King Abdulaziz

University, P.O.Box 80200, Jeddah, Saudi Arabia 